\title{
Development of a Mobile Module-Based Wind Tunnel for the Determination of Collection Efficiencies of Particulate Matter on Surface Structures
}

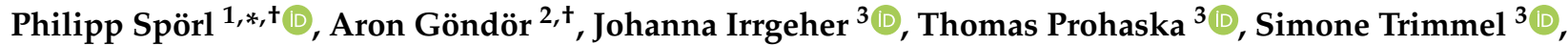 \\ Leo Capari ${ }^{4}$, Daniela Haluza ${ }^{4}$ (D), Bernhard Scharf ${ }^{1}$, Anne Kasper-Giebl ${ }^{2}$ and Ulrike Pitha ${ }^{1, *(\mathbb{D}}$
}

1 Institute of Soil Bioengineering and Landscape Construction, University of Natural Resources and Life Sciences, Vienna (BOKU), Peter-Jordan-Straße 82, 1190 Vienna, Austria; bernhard.scharf@boku.ac.at

2 Institute of Chemical Technologies and Analytics, TU Wien, Getreidemarkt 9/164, 1060 Vienna, Austria; aron.goendoer@tuwien.ac.at (A.G.); anneliese.kasper-giebl@tuwien.ac.at (A.K.-G.)

3 General and Analytical Chemistry, Montanuniversität Leoben, Franz Josef-Straße 18, 8700 Leoben, Austria; johanna.irrgeher@unileoben.ac.at (J.I.); thomas.prohaska@unileoben.ac.at (T.P.); simone.trimmel@unileoben.ac.at (S.T.)

4 Department of Environmental Health, Center for Public Health, Medical University of Vienna, Kinderspitalgasse 15, 1090 Vienna, Austria; leo.capari@meduniwien.ac.at (L.C.); Austria; daniela.haluza@meduniwien.ac.at (D.H.)

Citation: Spörl, P.; Göndör, A.; Irrgeher, J.; Prohaska, T.; Trimmel, S.; Capari, L.; Haluza, D.; Scharf, B.; Kasper-Giebl, A.; Pitha, U. Development of a Mobile Module-Based Wind Tunnel for the Determination of Collection Efficiencies of Particulate Matter on Surface Structures. Sustainability 2021, 13, 9565. https://doi.org/10.3390/ su13179565

Academic Editor: Ali Elkamel

Received: 9 July 2021

Accepted: 19 August 2021

Published: 25 August 2021

Publisher's Note: MDPI stays neutral with regard to jurisdictional claims in published maps and institutional affiliations.

Copyright: (c) 2021 by the authors. Licensee MDPI, Basel, Switzerland. This article is an open access article distributed under the terms and conditions of the Creative Commons Attribution (CC BY) license (https:/ / creativecommons.org/licenses/by/ $4.0 /)$.
* Correspondence: Philipp.spoerl@boku.ac.at (P.S.); ulrike.pitha@boku.ac.at (U.P.)

+ These authors contributed equally to this work.

\begin{abstract}
Ambient air pollutants are a global public health problem accounting for millions of annual deaths. A mobile module-based wind tunnel (WT) was developed to investigate the interaction between airborne particulate matter and various surface structures. The external dimensions were $4.33 \mathrm{~m} \times 1.96 \mathrm{~m} \times 1.73 \mathrm{~m}(l w h)$. The tunnel provided a cross-section of $0.40 \mathrm{~m} \times 1.10 \mathrm{~m}(w h)$ and a total volume of $2.84 \mathrm{~m}^{3}$. An exchangeable test section in the WT offered a vertical area of one square meter to introduce variable installations. Due to the modular design, the WT could be divided into seven segments. This enables flexibility in setting, easy transport and set up at different locations. Atmospheric parameters (temperature, humidity, flow speeds and flow directions) were measured. At the test section, determined flow speeds ranged from 0.3 to $2.6 \mathrm{~m} \mathrm{~s}^{-1}$, with turbulence intensities detected between $9 \%$ and $11 \%$ and Reynold numbers from 10,000 to 90,000. Losses of ambient PM within the blank tunnel were less than $10 \%$ for particle counts $(>0.25 \mu \mathrm{m})$, while smaller losses were obtained for $\mathrm{PM}_{1}$ and $\mathrm{PM}_{2.5}$. Thus, the construction, performance, as well as the limitations and various possible applications of the WT are shown in this article.
\end{abstract}

Keywords: wind tunnel; development; particulate matter; removal rate; green infrastructure

\section{Introduction}

The increase in air pollution is a worldwide problem that negatively affects the health of humans and ecosystems [1]. Hazardous substances enter the environment through a range of natural and anthropogenic activities. Air pollutants include carbon monoxide, sulfur dioxide, nitrogen oxides, volatile organic compounds, ground-level ozone, along with heavy metals and elemental carbon found in particulate matter (PM) including $\mathrm{PM}_{2.5}$ and $\mathrm{PM}_{10}$ (i.e., PM with an aerodynamic diameter of less than 2.5 or $10 \mu \mathrm{m}$, respectively). Air pollutants affect human health acutely and chronically by targeting several different organs, mainly the respiratory and the cardiovascular system [1,2]. Individuals with preexisting lung diseases, older adults and children are particularly at risk, with PM exposure negatively impacting lung development in the latter group [3]. The European Union emission control legislation has led to a decrease in $\mathrm{PM}_{2.5}$ concentrations in ambient air. Modelling suggests that the current EU limit value for $\mathrm{PM}_{2.5}$ of $25 \mu \mathrm{g} / \mathrm{m}^{3}$ as the annual 
mean concentration will be met by 2030 without further policy action. Likewise, this modelling also shows that the limit values for $\mathrm{PM}_{2.5}$ set by the WHO cannot be achieved in all EU states without further measures [4].

Given the negative public health impacts of inhalable PM, there is a great interest in clean(ing) ambient air. A very effective cleaning method is the use of vegetation around human settlements [5]. Various field studies, reviewed by Wania et al. [6], investigated the PM removal potential of green infrastructure (GI) via different approaches, including deposition assessments of pollutants through gravimetric methods, microscopy imaging techniques, but also roadside in situ concentration measurements. These studies reached different conclusions depending on the vegetation features, the geometrical characteristics of the inspected microenvironments, the meteorological conditions and the chosen measurement parameters and techniques [6]. Overall, the evidence for air quality improvement through GI is mixed, as an improperly designed implementation of vegetation can reduce pollutant dispersion at certain locations [7,8]. Nevertheless, the deposition of PM on plants can act as an additional important tool to remove pollutants in the air [9]. In general, PM with a large fraction size are more easily removed from air, whereas the more hazardous smaller particles are filtered to a lesser extent [5]. The efficiency of plants as biological air filters depends on both the season and the applied plant species. In winter time, only evergreen species are able to provide benefits in relation to air quality, while in full leaf, deciduous broad-leafed species are of more significant importance [10]. Apart from cleaning ambient air, this GI also delivers good results in improving indoor air quality. As an example, recent developments have led to activated green wall technology systems where air is moved actively through the substrate to increase the filtration rates of pollutants. These so-called botanical biofilters have the ability to reach total PM removal efficiencies of more than $50 \%$ [11]. In a study by Gopalakrishnan et al. [12], it was shown that the use of plants as air filters is comparable with technological solutions in relation to the efficiency of the removal of particulate matter and gaseous pollutants from the air. Moreover, GI can usually be implemented at very low costs.

Due to the lack of knowledge about the PM binding efficiency of plants and different surfaces, wind tunnels (WT) are often used to measure the collection efficiency or the concentration of PM on surfaces. Their applications are diverse and specifically targeted at certain structures or PM compositions. The classification of different WT constructions in general can be divided according to size, generatable wind speeds or type of application. The high variation of WT constructions results from the fact that the tunnel design strongly depends on the respective application. Their development is a step-by-step process [13].

Particle deposition characteristics in ventilation ducts and in WTs have already been studied extensively and the main PM removal mechanisms for different size fractions under various conditions have been pointed out [14-16]. Turbophoresis, Brownian diffusion, turbulent diffusion and gravitational settling were observed as the primary processes that lead to particle deposition in turbulent duct flows [9]. Specific particle deposition velocities were connected with flow velocities and surface types, confirming the significance of interception and impaction for aerosols of specific size ranges [17].

The main aim of this study was to develop a wind tunnel to investigate particulate matter accumulations on vertical and horizontal surface structures. We constructed the WT in such a way that modules with different surface structures can be clamped in the channel to determine PM accumulation efficiency. Since meteorological parameters influence the local concentration as well as the transport behavior of the particles, the atmospheric parameters were examined in the tunnel to determine correlations with the accumulation on different surfaces. We focused on the modular design and compactness of the construction to allow for measurements at different locations in an urban, but also a peri-urban and off-road environment.

Therefore, a methodology to determine the collection efficiency of PM on different surfaces, such as green infrastructures in the form of green facades but also any other design of facades is given, since a WT in this regard does not exist. The developed WT 
can be used in further experiments to explore suitable surfaces to reduce air pollution and consequently to contribute to public health. The limitations of the study are apparent in relation to the achievable flow speeds and the additional restriction of the vertical test section to $1 \mathrm{~m}^{2}$.

This study covers the development of the wind tunnel and the verification of the requirements developed in a test run. Furthermore, suggestions for optimization are discussed.

\section{Methods}

The structure of this study was divided into three different steps, as shown in Figure 1. Steps 1 and 2 focused on the method of development and the associated literature research and the planning and construction of the WT. Step 3 described the methodology for investigating the functionality of the WT.

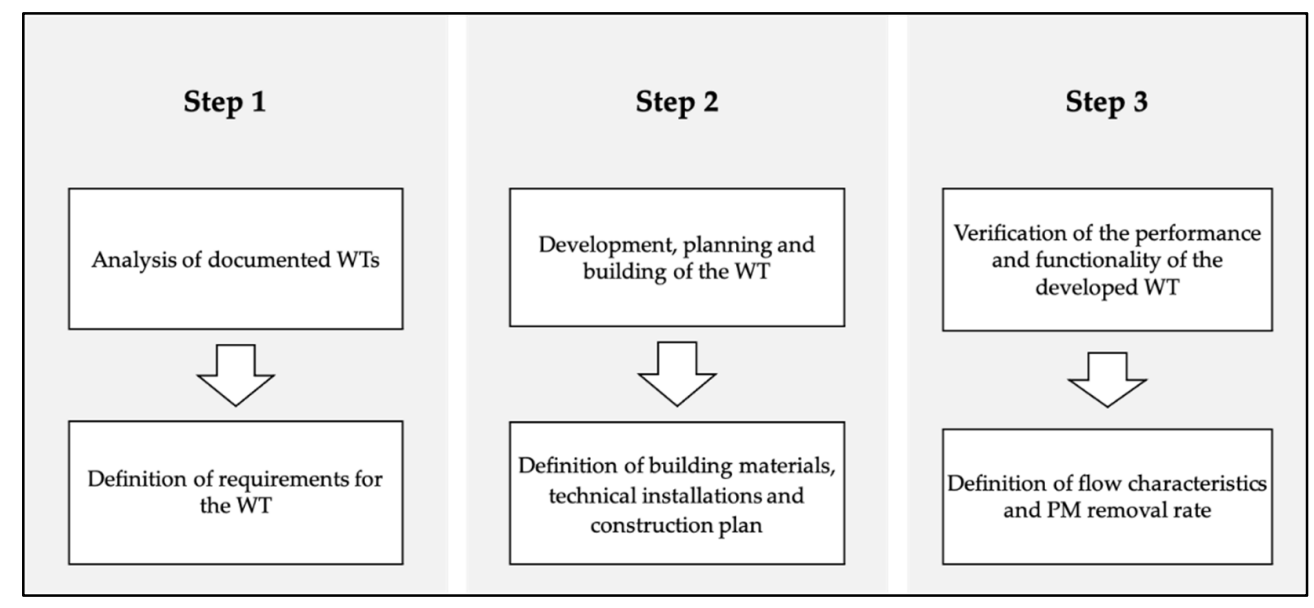

Figure 1. Process and concept of wind tunnel development in three steps.

\subsection{Step 1: Analysis of Documented WTs and Definition of Requirements for the WT}

The development of this WT was based on the study "Fundamentals of wind-tunnel design" by Cattafesta et al. [13]. In order to develop the WT in relation to the requirements described there, a comprehensive literature search was carried out additionally in a targeted manner. Thereby the purpose, design and technical features were considered. The resulting findings were used to create a list of requirements and materials for the WT.

\subsection{Step 2: Planning and Building the WT}

In the second step, technical drawings were prepared based on the results of the literature research. The dimensions of the individual components were defined as well as the exact positions of the technical equipment. The final construction of the wind tunnel was completed in Groß-Enzersdorf, Austria at the study site of the Institute of Soil Bioengineering and Landscape Construction of the University of Natural Resources and Life Sciences, Vienna (BOKU).

\subsection{Step 3: Verification of the Performance and Functionality of the Developed WT}

The characteristics and efficiency of the WT were further characterized in detail. For this purpose, a field test was carried out with three different fan speed levels in November 2020 in Groß-Enzersdorf, Austria $\left(48^{\circ} 11^{\prime} 50.8^{\prime \prime}\right.$ N 16 $33^{\circ} 40.8^{\prime \prime}$ E). The WT was located at distance of approximately $4 \mathrm{~m}$ to the main road at the entrance to the town. Particulate matter data from two optical particle counters (OPC) were monitored during the experiment. Possible influences of atmospheric parameters such as flow speed, flow direction, humidity and temperature were determined. 


\subsubsection{Quality Assurance with Regard to PM Measurement Data}

To ensure the comparability of the two OPCs, the instruments were run in parallel several times under ambient conditions at a minimum distance between their inlets. A data set covering $7.5 \mathrm{~h}$ distributed across a period of 8 separate days of sampling was compiled. Eight comparability measurements were carried out within a period of 3 weeks. The corresponding mean minute values of the mass concentrations of $\mathrm{PM}_{10}, \mathrm{PM}_{2.5}, \mathrm{PM}_{1}$ and total counts (TC) regarding the number of concentrations above $0.25 \mu \mathrm{m}$ optical particle diameter were compared by statistical tests. If the differences between the paired values showed a normal distribution, a parametric test (paired Student's $t$-test) was carried out to check for significant discrepancies $(\alpha=5 \%)$ between the assessed values recorded by the two OPCs. Otherwise, a non-parametric test (Wilcoxon signed rank test) was used for evaluation. All statistical evaluations were executed via Datalab (ver. 3.965). Although both instruments were calibrated before the measurement campaign, the statistical analyses identified significant divergences for all measured parameters, except for total suspended particles (TSP). Consequently, all parameters were adjusted through linear regression models, derived from the relationship between the two instruments. Following these corrections, the discrepancies were eliminated with no further significant differences identifiable by the aforementioned statistical tests. Therefore, these regression models were used for the adjustments of the data set collected in the subsequent experiments. The agreement obtained for the TSP values was instead induced by the high variability for these mass concentrations rather than by a perfect fit; thus, the TSP parameter was not evaluated further. Parallel comparability measurements allowed the error of single data points to be calculated, expressed as the mean of the percentual differences of the two monitors. The average relative discrepancies of the parameters $\mathrm{PM}_{10}, \mathrm{PM}_{2.5}, \mathrm{PM}_{1}$ and TC amounted to around $11 \%, 5 \%, 3 \%$ and $2 \%$, respectively.

The size distributed particle number concentrations covering twenty channels from $0.25 \mu \mathrm{m}$ to $5 \mu \mathrm{m}$ were merged into five new classes, with logarithmically equidistant midpoint optical particle diameter bins of $0.3 \mu \mathrm{m}, 0.49 \mu \mathrm{m}, 0.83 \mu \mathrm{m}, 1.9 \mu \mathrm{m}, 4 \mu \mathrm{m}$ and $8.25 \mu \mathrm{m}$ and adjusted as explained above. Again, the largest particles with a midpoint optical particle diameter of $8.25 \mu \mathrm{m}$ and above showed the largest variation and have to be interpreted with caution.

\subsubsection{Calculation of the Flow Characteristics Inside the WT}

The flow behavior was evaluated to obtain further information about the air movements within the WT. For this purpose, the Reynolds number (Re) was used. This number is dimensionless and is calculated from the ratio of inertial to viscous forces. The calculation includes the average flow speed in $\mathrm{m} \mathrm{s}^{-1}\left(U_{\infty}\right)$, the hydraulic diameter in $\mathrm{m}\left(D_{\mathrm{h}}\right)$ and the kinematic viscosity in $\mathrm{m}^{2} \mathrm{~s}^{-1}(v)[18,19]$.

$$
\operatorname{Re}=\frac{D_{h} U_{\infty}}{v}
$$

In addition to the Reynolds number, the turbulence intensity (I) was calculated from the results of the sensor data. This value is defined as the ratio of the standard deviation $\left(U_{\infty}{ }^{\prime}\right)$ of the fluctuating air flow to the average flow speed $\left(U_{\infty}\right)$ and represents the intensity of the wind flow fluctuation [13].

$$
I=\frac{U_{\infty} \prime}{U_{\infty}}
$$

\section{Results}

According to the methodology described in Section 2, the results followed three individual steps. These were based on each other and were necessary to form the wind tunnel construction in Step 1 and 2 and to check the properties of the WT in Step 3. 


\subsection{Evaluation of WTs from the Literature and a Definition of the Requirements Placed on the Design of a WT (Step 1)}

From the literature review, five different WTs used in various studies were evaluated in more detail. Their main characteristics and areas of application are summarized in Table 1.

Table 1. Main properties and type of application of five different WTs.

\begin{tabular}{ccccc}
\hline Name/Publication & Length & Cross-Section & Flow Speeds Used & Areas of Application \\
\hline $\begin{array}{c}\text { Trent Environmental Wind Tunnel } \\
\text { (TEWT)/McKenna et al.; Richards } \\
\text { T. et al. and Preston et al. [20-22] } \\
\text { Aeolian Simulation Laboratory } \\
\text { (BGU)/Katra et al. [23,24] }\end{array}$ & $12.5 \mathrm{~m}$ & $0.54 \mathrm{~m}^{2}$ & up to $12 \mathrm{~m} \mathrm{~s}^{-1}$ & $\begin{array}{c}\text { Dust emission, physics of particle } \\
\text { transport, air quality, wind erosion, } \\
\text { climatic effects }\end{array}$ \\
$\begin{array}{c}\text { Franco et al. and Valera et al. } \\
\text { [25,26] }\end{array}$ & $10 \mathrm{~m}$ & $0.25 \mathrm{~m}^{2}$ & up to $18 \mathrm{~m} \mathrm{~s}^{-1}$ & $\begin{array}{c}\text { Dust emission, wind erosion, } \\
\text { particulate matter on surfaces }\end{array}$ \\
$\begin{array}{c}\text { Evaporative cooling, substrate } \\
\text { analysis, agro-textiles }\end{array}$ \\
$\begin{array}{c}\text { IRPHE/Roupsard et al. [17] } \\
\begin{array}{c}\text { Simultaneous Water and Wind } \\
\text { Erosion Simulator }\end{array}\end{array}$ & $0.38 \mathrm{~m}^{2}$ & up to $10 \mathrm{~m} \mathrm{~s}^{-1}$ & up to $9.9 \mathrm{~m} \mathrm{~s}^{-1}$ & $\begin{array}{c}\text { Submicron aerosol deposition on } \\
\text { urban surfaces, vertical } \\
\text { measurements }\end{array}$ \\
$\begin{array}{c}\text { (SWWES)/Mahmoodabadi et al. } \\
\text { and Kheirabadi et al. [27,28] }\end{array}$ & $12 \mathrm{~m}$ & $0.17 \mathrm{~m}^{2}$ & upt to $30 \mathrm{~m} \mathrm{~s}^{-1}$ & $\begin{array}{c}\text { Sediment transport, simulation of } \\
\text { rain and wind }\end{array}$ \\
\hline
\end{tabular}

The Trent Environmental Wind Tunnel (TEWT) was used in a study on $\mathrm{PM}_{10}$ emission rates from ash by Richard-Thomas et al. [21]. The WT had an open-loop, straight-line suction design. The WT inlet consisted of a honeycomb straw filter that kept the airflow straight and minimized turbulence. In addition, a roughness field of wooden dowels was installed at this point to develop a turbulent boundary layer. The motor speed used in this WT was a microprocessor controlled to ensure a smooth airflow. The wind speeds were measured with micro pitot tubes [22]. The other technical installations for measurements were a Dantec 2-component Laser Doppler anemometer, a Konica-Minolta Vivid 9i noncontact 3D digitizer, a PCO high-speed digital camera, TSI DustTrak aerosol monitors and Sensit, Wenglor particle counters [29]. In order to create controlled atmospheric conditions, the duct was installed inside a climatic chamber which allowed the regulation of air temperature and air humidity [20-22].

In a study on wind-induced dust emission from unpaved roads and a study on the modelling of particulate matter transport in atmospheric boundary layers, an openbottom boundary layer wind tunnel from the Aeolian Simulation Laboratory at Ben Gurion University (BGU) was used $[23,24]$. The $\mathrm{PM}_{10}$ particle size fraction was measured by a real-time dust monitor (DustTrak 8534, TSI). The tunnel was transportable and could therefore be used in the field $[23,24]$. Katra et al. also observed different surfaces in a horizontal plane to reduce dust emissions from surface treatments compared to unpaved roads. Materials such as brine, lignin, resin, bitumen and PVA were used [23].

Another example of a WT is the slow speed wind tunnel used in a study by Valera et al. [25]. It was constructed to investigate insect-proof mesh sieves and was also utilized for studies about active living walls. The WT had a total length of $4.74 \mathrm{~m}$, a circular cross-section of $0.38 \mathrm{~m}^{2}$ and was operated in an open circuit. The basic structure of the WT included the following subdivisions: flow conditioner, contraction, test section, diffuser, and fan. The airflow was accelerated by a conical contraction section, so that airflows of up to $10 \mathrm{~m} \mathrm{~s}^{-1}$ could be achieved with an axial fan (HCT-45 Sodeca S.A, Barcelona, Spain) of $2.865 \mathrm{rpm}$ and a maximum volumetric flow of $12.800 \mathrm{~m}^{3} / \mathrm{h}$. For the speed regulation of the fan, a Micromaster 420 AC (Siemens, Munich, Germany) was installed and controlled via a microprocessor with a computer. Two pitot tubes (Airflow Developments Ltd., High Wycombe, UK) were used to measure the static pressure. The flow speed and temperature 
were measured with a directional hot film anemometer (EE70-VT32C5, E+E Elektronik, Engerwitzdorf, Austria) [26].

In a study by Roupsard et al. [17] with urban surfaces in a WT experiment measuring the dry deposition velocities of a submicron aerosol, a recirculating WT was used. This recirculating WT at the University of Aix-Marseille, campus of Luminy, Marseille, France (IRPHE) was able to sample vertical surfaces and had a test section made of glass and a steel base. The laboratory tests with flow speeds of 1.3, 5.0 and $9.9 \mathrm{~m} \mathrm{~s}^{-1}$ were on a glass surface, cement cladding and synthetic grass.

Another example is the WT of the Simultaneous Water and Wind Erosion Simulator (SWWES) of the Soil Erosion and Conservation Laboratory at Shahid Bahonar University, Kerman, Iran. In this study, an axial fan was used with an electric motor of $15 \mathrm{hp}$ and $3000 \mathrm{rpm}$. The resulting mean wind speeds were measured with a hot-wire anemometer (TES-1340, Taipei, Taiwan) at 24 different heights and the shear velocity was determined [28]. The special feature of this WT was that a rain simulator was installed, which could generate rain intensities from 20 to $200 \mathrm{~mm} \mathrm{~h}^{-1}$. This WT was used to study the simultaneous effect of wind and rain and to measure and model soil loss [27].

As previous studies have shown, designs often vary depending on the area of application. The construction methods differ primarily regarding closed constructions or open constructions, the size of the test-and cross-sections and the flow speeds achieved [20,21,23-28]. The following requirements were predefined for the design of our WT:

- To ensure transportability, the overall construction should not exceed the external dimensions of $5 \mathrm{~m} \times 2.5 \mathrm{~m} \times 2 \mathrm{~m}$;

- The WT should be dismountable into individual segments that do not exceed a width of $0.8 \mathrm{~m}$ in order to fit through doors;

- A division of the WT must include a pre- and post-condition zone, as well as a measuring section;

- An exchangeable test section of the specimens should be at least one square meter with vertical surfaces;

- The material should not be metallic or electrostatically chargeable;

- The wind flow should be up to a maximum of $2.5 \mathrm{~m} \mathrm{~s}^{-1}-3.0 \mathrm{~m} \mathrm{~s}^{-1}$;

- The angle of inflow of the test section should be approximately $90^{\circ}$ to the sensor position

- $\quad$ To check the prevailing climatic conditions, the WT must be able to measure temperature, humidity, flow direction and flow speed;

- To ensure plant growth, growth lamps must be installed;

- Input and output variables (mass and number concentrations) of PM must be measurable.

\subsection{Used Materials, Technical Components and the Construction of the WT (Step 2)}

Based on the list resulting from the literature research in Step 1, the building materials, the construction plan of the WT including the technical equipment and the construction details as well as the dimensions were developed in Step 2.

\subsubsection{Building Materials}

Wood was used for the construction as the predefined requirements excluded metal and plastic. It was also used for financial reasons. We also used screen printing plates with a phenolic resin coating. To meet the requirements for non-metallic or electrostatic materials, mounting brackets were not integrated inside the tunnel and consequently an exoskeleton made of wood was constructed. The materials used are shown in Table 2. Except for individual screw connections, metallic materials were located exclusively outside the WT construction. 
Table 2. List of building materials used.

\begin{tabular}{ccccc}
\hline Name & Material/Details & $\boldsymbol{l} \mathbf{( \mathbf { m m } )}$ & $\boldsymbol{w} \mathbf{( \mathbf { m m } )}$ & $\boldsymbol{h} \mathbf{( \mathbf { m m } )}$ \\
\hline $\begin{array}{c}\text { solid structural } \\
\text { timber }\end{array}$ & spruce/fir & various & 45 & 70 \\
\hline screen-printing plate & $\begin{array}{c}\text { birch (phenolic resin } \\
\text { coating) }\end{array}$ & various & various & 12 \\
\hline \multirow{2}{*}{ swivel castor } & $\begin{array}{c}\text { wheel diameter } 100 \mathrm{~mm} ; \\
\text { wheel width 30 mm }\end{array}$ & $\begin{array}{c}102 \text { (mounting } \\
\text { plate) }\end{array}$ & $\begin{array}{c}83 \text { (mounting } \\
\text { plate) }\end{array}$ & 129 \\
\hline tension locks & stainless steel & 75 & 26.5 & 16.5 \\
\hline
\end{tabular}

\subsubsection{Technical Installations and Measuring Equipment}

Five two-dimensional wind velocity and wind direction sensors (ATMOS 22 Ultrasonic Anemometer, METER Group AG, Munich, Germany) were used. Furthermore, three air temperature and relative humidity sensors (ATMOS 14 temperature and relative humidity sensor, METER Group) were utilized. Four growth lamps (DIW LED Spot V $4200 \mathrm{~K} / 90 / 16^{\circ}$ $22 \mathrm{~W}$, München, Germany) were installed for the planted surfaces to guarantee plant growth inside the tunnel. The WT was operated with an AC axial fan with the following data: $5000 \mathrm{~m}^{3} / \mathrm{h}, 240 \mathrm{~V}$ ac, $0.54 \mathrm{~m} \times 0.54 \mathrm{~m} \times 0.165 \mathrm{~m}(l \times w \times h), \varnothing=0.4 \mathrm{~m}$ rotor blade, $300 \mathrm{~W}$ (ebm papst, Mulfingen, Germany). A fan speed controller was used for a step-less regulation of the flow speed.

The characterization of ambient particulate matter concentrations was performed by two optical particle counters (OPC) (Mini-LAS 11E, GRIMM Aerosol Technik GmbH \& Co. KG, Ainring, Germany). The OPC determined the temporal changes in PM number concentrations, covering 31 size channels in the range from 0.25 to $32 \mu \mathrm{m}$, yielding the total count (TC) through the aggregation of all channels. The recorded number concentrations were also converted into the corresponding mass concentration values (TSP, $\mathrm{PM}_{10}, \mathrm{PM}_{2.5}$, $\mathrm{PM}_{1}$ ) based on the software of the OPC (Grimm Aerosol Technik GmbH \& Co. KG 1178 V8-1, Rev IV compiled 23 June 2020). The initial time resolution of the optical particle counter was $6 \mathrm{~s}$, which was converted into minute average values.

In addition, an electrical low-pressure impactor (ELPI) (Dekati model: 2E10-10, Software Version ELPI+ VI2.1, Kangasala, Finland) was operated to assess smaller size classes in the ultra-fine particles range (UFP; i.e., PM with an aerodynamic diameter of less than $0.1 \mu \mathrm{m})$.

\subsubsection{The Dimensions and Main Features of the Wind Tunnel Construction}

Figure 2 shows the main features of the construction and the technical characteristics. The tunnel can be divided into four parts with a pre-condition zone, a measuring section, a replaceable vertical test section and a post-condition zone. To prevent further wind turbulences and to minimize the influence on the PM entering the WT, the fan was installed in suction mode. The external dimensions of the WT were $4.33 \mathrm{~m} \times 1.96 \mathrm{~m} \times 1.73 \mathrm{~m}$ $(l \times w \times h)$. The tunnel had a cross-section of $0.40 \mathrm{~m} \times 1.10 \mathrm{~m}(w \times h)$ as well as a measuring section with $1.70 \mathrm{~m} \times 0.40 \mathrm{~m} \times 1.10 \mathrm{~m}(l \times w \times h)$ and a vertical test section of $1.10 \mathrm{~m} \times 1.10 \mathrm{~m}(w \times h)$. The replaceable test section allowed measurements within a surface area of approximately $1 \mathrm{~m}^{2}$. The base area of the wind tunnel was $2.59 \mathrm{~m}^{2}$ with the inner wall installed in a range of $0.40 \mathrm{~m}$ to the test section (Figure 2). The height inside the WT was $1.10 \mathrm{~m}$ at each point, resulting in a total volume of $2.84 \mathrm{~m}^{3}$. The total internal surface area in the WT with the test module in place was $14.91 \mathrm{~m}^{2}$, excluding the tunnel end where the axial fan was installed. 


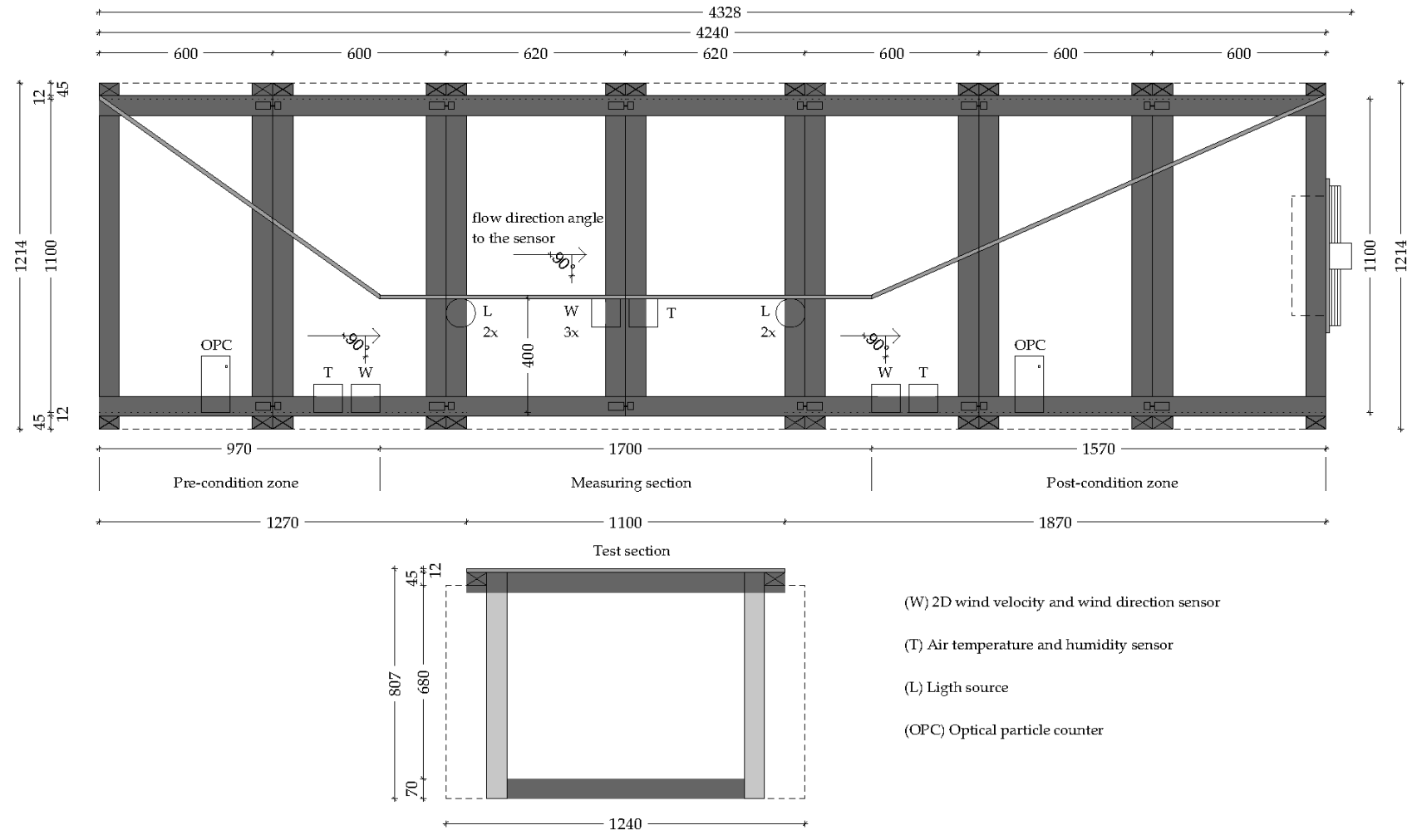

Figure 2. Ground plan of the wind tunnel construction and the technical features.

\subsubsection{Construction Details}

During the construction of the tunnel, the modular system enabled indoor and outdoor usage and guaranteed easy transport of the WT. The flat construction was made of $12 \mathrm{~mm}$ wooden screen-printing plates. Moreover, the individual plates were screwed into segments using an exoskeleton. A detailed material list for the construction of the WT is presented in Table 2.

The WT consisted of seven segments, which were connected using tension locks to form an angled tunnel and were located on substructures made of wooden beams with four heavy-duty castors each. The segments could optionally be reduced to five segments. For the indoor usage of the WT or in climatic chambers, the width of the segments was limited to a maximum of $0.62 \mathrm{~m}$ to facilitate transportation. Inside the tunnel, a partition wall was installed and the zone in the measurement of $0.40 \mathrm{~m}$ width narrowed. Thus, higher flow speeds could be achieved, and the climatic conditions were measured close to the surfaces. Moreover, the pre-condition zone allowed the airflow in this region with a flow direction of $90^{\circ}$ angle to the sensors close to the test section shown in Figure 2.

The exchangeable test section was designed in such way that it had an inner surface of $1.10 \mathrm{~m} \times 1.10 \mathrm{~m}$ when inserted into the wind tunnel. This meant that vertical surfaces could be tested on approximately one square meter. The maximum installation depth of the test surfaces on the module was $0.40 \mathrm{~m}$ to the inner wall. Optionally, these could be moved further back to increase the installation depth. The axial fan was positioned centrally at the end of the tunnel and served as a suction fan. An overlying, removable roof construction made of phenolic resin-coated screen-printing plates protected the WT from rain (Figure 3). 

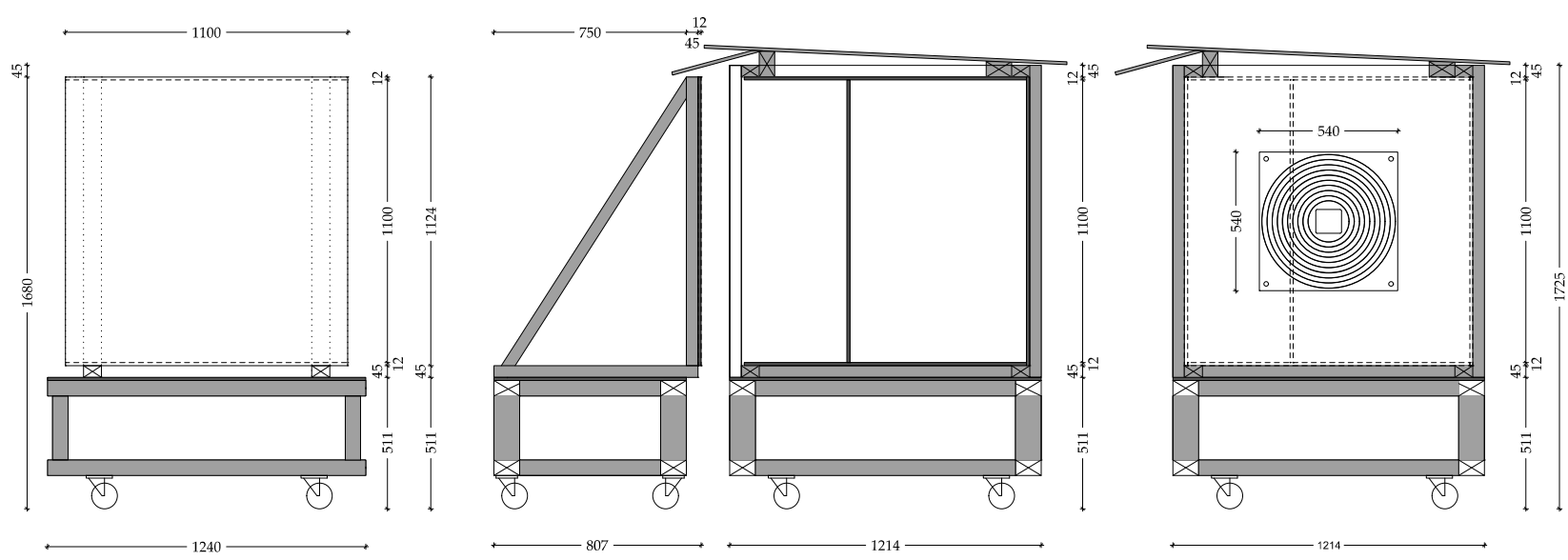

Figure 3. Construction details (profiles) of the replaceable test section and the roof of the WT.

\subsubsection{Sensor Positions}

For an overall impression of the air flows, velocities and particle concentrations, sensors were arranged cross-shaped inside the WT. The positions a-e of the sensors are shown in Figure 4. The sensors a-c were located opposite the test section and the positions $\mathrm{d}$ and e were on the side of the test section at a medium height. Accordingly, the flow direction and flow speed $(\mathrm{W})$ could be measured at three different heights $(\mathrm{a}-\mathrm{c})$ directly opposite the vertical test section. The input and output variables of ambient PM were determined at positions d and e via an optical particle counter (OPC) at a height of $0.40 \mathrm{~m}$ with respect to the WT floor. Temperature and humidity $(\mathrm{T})$ were also measured at positions $\mathrm{d}$ and e. Four growth lamps (L) were positioned opposite the test section.

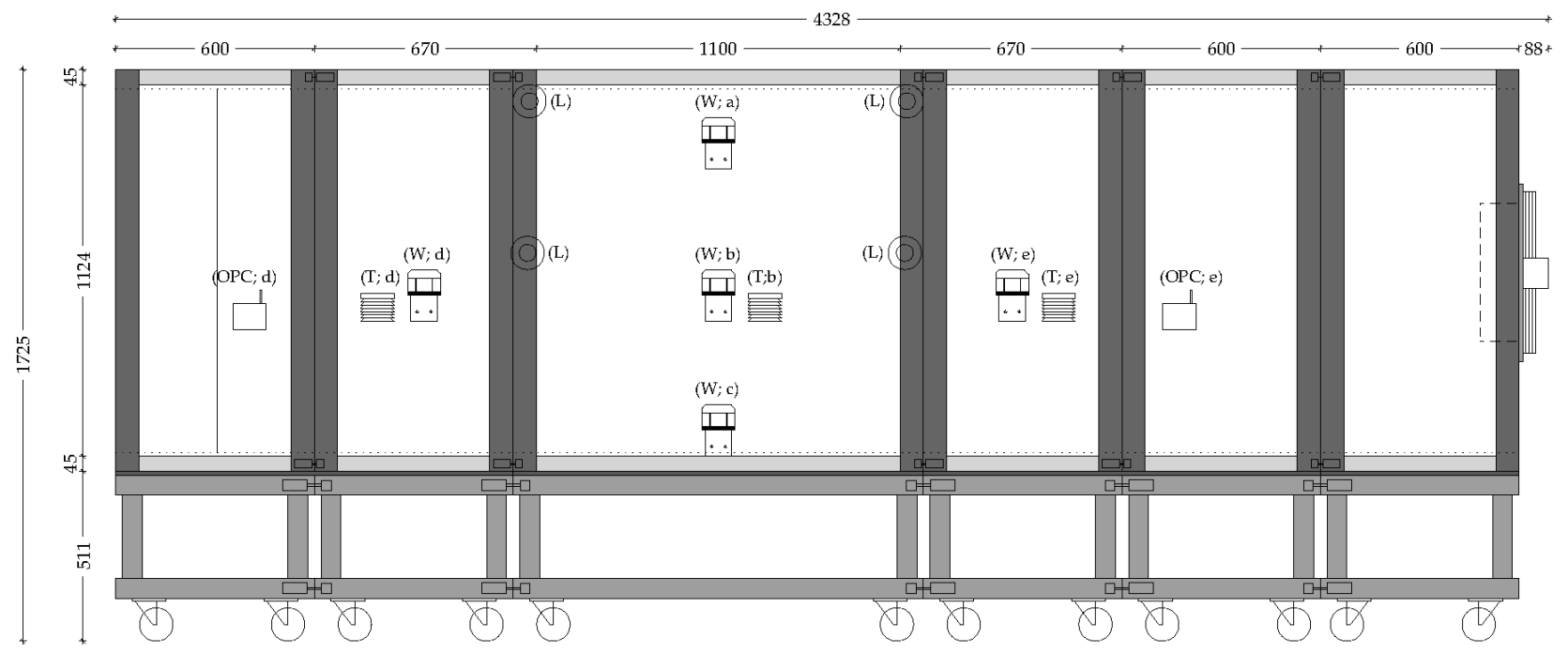

Figure 4. Vertical section of the WT-sensor positions a-e; OPC = optical particle counter; $\mathrm{W}=$ flow direction, flow speed; $\mathrm{T}=$ temperature, humidity; $\mathrm{L}=$ growth lamp.

\subsubsection{Wind Tunnel Characteristics}

As an open system with an opening cross-section of $1.21 \mathrm{~m}^{2}$, the tunnel was designed to operate with ambient air. Due to the individual segments, the WT could easily be removed, set up and transported (Figure 5). This enables flexible use at different locations, for both indoor and outdoor measurements. To determine the relationship between the atmospheric parameters and the amount of PM deposited on the surfaces, temperature and humidity were also logged. 

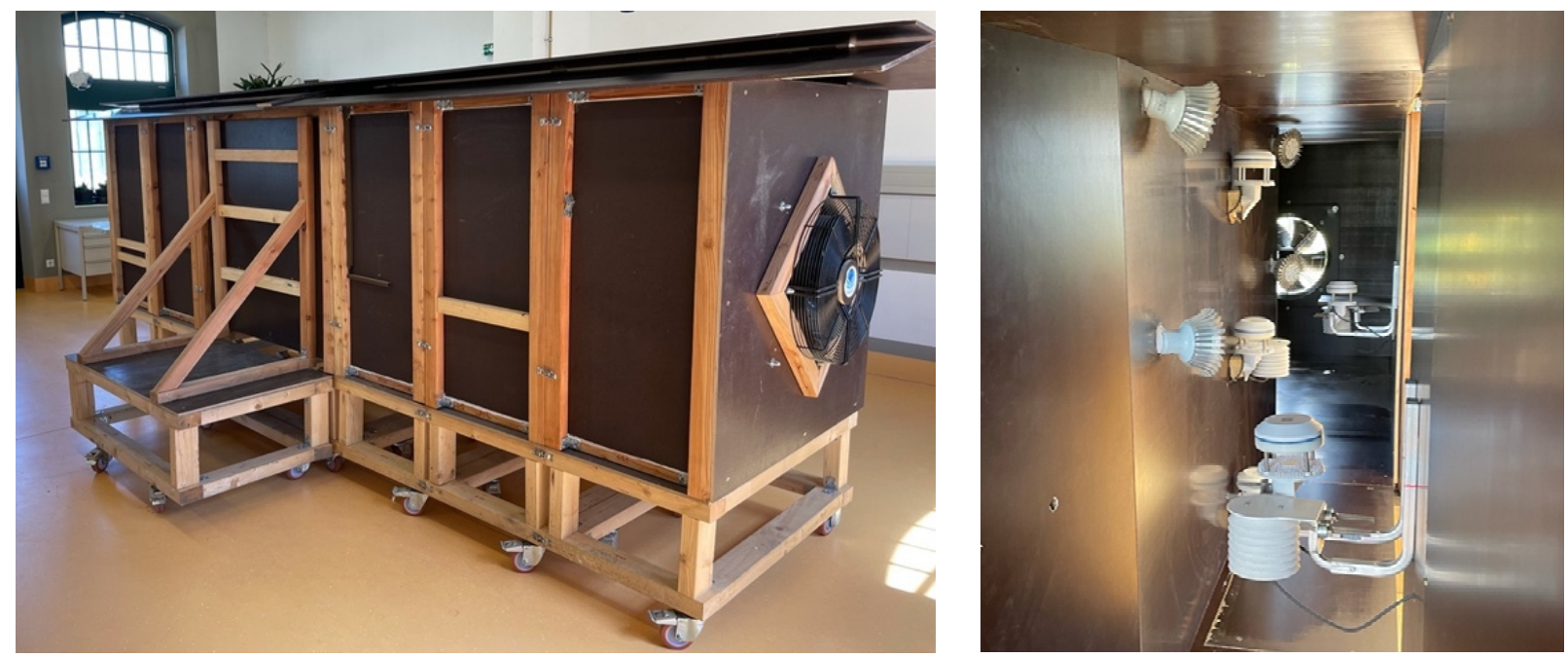

Figure 5. Completed wind tunnel consisting of 7 segments exterior (left) and interior view (right). The interior view shows the positioning of the sensors and lighting with a view towards the axial fan.

\subsection{Results of the Functionality of the WT and Properties Calculated from It (Step 3)}

In the final development step and in order to make suggestions for the improvement of the design with respect to the list of requirements developed in Step 1, the sensor data was evaluated. Based on the data, calculations of the air flow behavior at the test section and the calculation of the removal rate were carried out.

\subsubsection{Results of Atmospheric Parameters with a Smooth Vertical Surface}

The measurement results from the two-hour test run time for the atmospheric parameters were divided into two parts. The first part was the pre-and post-condition zone with sensor positions $d$ and e shown in the top section of Table 3 . and the second part was the test section with sensor positions a-c shown in the bottom section of Table 3 .

Table 3. (Top) Mean values of flow direction, flow speed, temperature and relative humidity in the pre- and postconditioning zones, (d) and (e) respectively. (Bottom) Mean values of flow direction, flow speed, temperature and relative humidity in the test section at the top (a), middle (b) and bottom (c) sensor positions, respectively.

\begin{tabular}{|c|c|c|c|c|}
\hline Fan Speed Level & $\begin{array}{l}\text { Flow Direction } \\
\text { Pre-Conditioning } \\
\text { Zone }\left[{ }^{\circ}\right]^{*}\end{array}$ & $\begin{array}{c}\text { Flow Direction } \\
\text { Post-Conditioning } \\
\text { Zone }\left[{ }^{\circ}\right]^{*}\end{array}$ & $\begin{array}{l}\text { Flow Speed } \\
\text { Pre-Conditioning } \\
\text { Zone }\left[\mathrm{m} \mathrm{s}^{-1}\right]\end{array}$ & $\begin{array}{c}\text { Flow Speed } \\
\text { Post-Conditioning } \\
\text { Zone }\left[\mathrm{m} \mathrm{s}^{-1}\right]\end{array}$ \\
\hline Low $\left(t=60^{\prime}\right)$ & $81.30(\mathrm{SD}=3.89)(\mathrm{d})$ & $85.05(\mathrm{SD}=2.12)(\mathrm{e})$ & $0.68(\mathrm{SD}=0.05)(\mathrm{d})$ & $0.57(\mathrm{SD}=0.03)(\mathrm{e})$ \\
\hline Medium $\left(t=35^{\prime}\right)$ & $84.66(\mathrm{SD}=2.14)(\mathrm{d})$ & $83.51(\mathrm{SD}=2.19)(\mathrm{e})$ & $1.51(\mathrm{SD}=0.06)(\mathrm{d})$ & $1.28(\mathrm{SD}=0.04)(\mathrm{e})$ \\
\hline $\operatorname{High}\left(t=25^{\prime}\right)$ & $86.68(\mathrm{SD}=1.95)(\mathrm{d})$ & $83.48(\mathrm{SD}=1.29)(\mathrm{e})$ & $3.11(\mathrm{SD}=0.38)(\mathrm{d})$ & $2.66(\mathrm{SD}=0.33)(\mathrm{e})$ \\
\hline Fan Speed Level & $\begin{array}{l}\text { Temperature } \\
\text { Pre-Conditioning } \\
\left.\text { Zone }\left[{ }^{\circ} \mathrm{C}\right]\right]^{*}\end{array}$ & $\begin{array}{c}\text { Temperature } \\
\text { Post-Conditioning } \\
\text { Zone }\left[{ }^{\circ} \mathrm{C}\right]{ }^{*}\end{array}$ & $\begin{array}{c}\text { Relative Humidity } \\
\text { Pre-Conditioning } \\
\text { Zone [\%] }\end{array}$ & $\begin{array}{c}\text { Relative Humidity } \\
\text { Post-Conditioning } \\
\text { Zone [\%] }\end{array}$ \\
\hline $\operatorname{Low}\left(t=60^{\prime}\right)$ & $12.07(\mathrm{SD}=0.65)(\mathrm{d})$ & $12.20(\mathrm{SD}=0.76)(\mathrm{e})$ & $62.17(\mathrm{SD}=1.65)(\mathrm{d})$ & $60.93(\mathrm{SD} \mathrm{f}=2.06)(\mathrm{e})$ \\
\hline Medium $\left(t=35^{\prime}\right)$ & $10.28(\mathrm{SD}=0.14)(\mathrm{d})$ & $10.20(\mathrm{SD}=0.20)(\mathrm{e})$ & $68.12(\mathrm{SD}=0.95)(\mathrm{d})$ & $67.64(\mathrm{SD}=1.22)(\mathrm{e})$ \\
\hline $\operatorname{High}\left(t=25^{\prime}\right)$ & $10.02(\mathrm{SD}=0.07)(\mathrm{d})$ & $9.91(\mathrm{SD}=0.08)(\mathrm{e})$ & $70.01(\mathrm{SD}=0.33)(\mathrm{d})$ & $69.77(\mathrm{SD}=0.35)(\mathrm{e})$ \\
\hline
\end{tabular}

* Specified angle of the flow direction to the sensor shown in Figure 2.

The measurement of the angle of attack in the pre- and post-condition zones showed mean values between $81.30^{\circ}$ and $86.68^{\circ}$ with a maximum standard deviation of $3.39^{\circ}$ at low fan speeds. The resulting flow speeds in the pre-and post-condition zone showed, due to the installation of the partition wall and the associated tapering of the volume in the area of the pre-condition zone, an average acceleration of the air flow in the front area of the WT of $0.11 \mathrm{~m} \mathrm{~s}^{-1}$ to the post-condition zone at a slow fan speed level. The acceleration 
value increased at the other two set fan speed levels by $0.23 \mathrm{~m} \mathrm{~s}^{-1}$ at a medium fan speed and by $0.45 \mathrm{~m} \mathrm{~s}^{-1}$ at a high fan speed. Thus, the highest flow speeds were measured in the pre-conditioning zone for all fan speed levels, while flow speeds measured in the post-conditioning zone were reduced by $14 \%, 15 \%$ and $16 \%$ at low, medium and high fan speed levels, respectively. Similarly, the standard deviation increased to $0.38 \mathrm{~m} \mathrm{~s}^{-1}$ in the pre-conditioning zone at higher flow speeds. The mean value of the flow speed measured in the pre-conditioning zone even reached a value of $3.11 \mathrm{~m} \mathrm{~s}^{-1}$. Overall residence times within the WT were from $1.4 \mathrm{~s}$ to $7.6 \mathrm{~s}$, depending on the fan speed.

The measured temperature data showed no significant differences between the preand post-condition zones. The maximum value of $0.13{ }^{\circ} \mathrm{C}$ difference occurred at a low fan speed level and was, similar to the comparatively higher standard deviations, due to the longer test period. A similar situation emerged for the relative humidity. Here, a maximum difference of $1.24 \%$ relative humidity was recorded, which can be explained by the general reduction in temperature and the accompanying increase in humidity during the test period.

The range of flow directions in the test section shown in Table 4 was between $79.08^{\circ}$ and $96.36^{\circ}$. Here, a higher variability of the flow direction was shown at a lower fan speed level. At sensor position a, a maximum value of $11.03^{\circ}$ standard deviation was reached at a low flow speed. The most constant flow direction results of the sensor positions a-c were achieved with the highest fan speed level. In the test section, the mean flow speed values ranged from $0.28 \mathrm{~m} \mathrm{~s}^{-1}$ to $0.58 \mathrm{~m} \mathrm{~s}^{-1}$ (low fan speed), $1.00 \mathrm{~m} \mathrm{~s}^{-1}$ to $1.19 \mathrm{~m} \mathrm{~s}^{-1}$ (medium flow speed) and $2.14 \mathrm{~m} \mathrm{~s}^{-1}$ to $2.55 \mathrm{~m} \mathrm{~s}^{-1}$ (high flow speed). The measurement data in the test section clearly show that the fluctuation of the flow direction decreased with higher fan speeds. With these three different levels of speed, it can also be seen that the highest flow velocities prevailed in the lower area of the WT (sensor position c) with the same suction.

Table 4. Mean values of flow speed, flow direction, temperature and relative humidity in the test section, (a) = sensor position at the top; $(b)=$ sensor position in the middle; $(c)=$ sensor position at the bottom.

\begin{tabular}{ccccc}
\hline Fan Speed Level & Flow Direction $\left[^{\circ}\right]^{*}$ & Flow Speed $\left[\mathbf{m ~ s}^{-1}\right]$ & Temperature $\left[{ }^{\circ} \mathbf{C}\right]$ & Relative Humidity $[\%]$ \\
\hline \multirow{3}{*}{ Low $\left(t=60^{\prime}\right)$} & $88.38(\mathrm{SD}=11.3)(\mathrm{a})$ & $0.30(\mathrm{SD}=0.08)(\mathrm{a})$ & & \\
& $79.08(\mathrm{SD}=4.6)(\mathrm{b})$ & $0.28(\mathrm{SD}=0.03)(\mathrm{b})$ & $12.11(\mathrm{SD}=0.62)(\mathrm{b})$ & $61.61(\mathrm{SD}=1.55)(\mathrm{b})$ \\
& $95.58(\mathrm{SD}=2.3)(\mathrm{c})$ & $0.58(\mathrm{SD}=0.03)(\mathrm{c})$ & & \\
\hline & $86.66(\mathrm{SD}=1.54)(\mathrm{a})$ & $1.06(\mathrm{SD}=0.06)(\mathrm{a})$ & & \\
Medium $\left(n=35^{\prime}\right)$ & $92.31(\mathrm{SD}=1.98)(\mathrm{b})$ & $1.00(\mathrm{SD}=0.09)(\mathrm{b})$ & $10.32(\mathrm{SD}=0.17)(\mathrm{b})$ & $67.44(\mathrm{SD}=1.08)(\mathrm{b})$ \\
& $96.20(\mathrm{SD}=2.00)(\mathrm{c})$ & $1.19(\mathrm{SD}=0.06)(\mathrm{c})$ & & \\
\hline & $91.84(\mathrm{SD}=1.40)(\mathrm{a})$ & $2.14(\mathrm{SD}=0.25)(\mathrm{a})$ & & \\
& $93.92(\mathrm{SD}=1.22)(\mathrm{b})$ & $2.21(\mathrm{SD}=0.24)(\mathrm{b})$ & $9.96(\mathrm{SD}=0.07)(\mathrm{b})$ & $69.91(\mathrm{SD}=0.49)(\mathrm{b})$ \\
\hline
\end{tabular}

* Specified angle of the flow direction to the sensor shown in Figure 2.

Overall, it can be said that a flow velocity range with a minimum velocity of $0.28 \mathrm{~m} \mathrm{~s}^{-1}$ and a maximum velocity of $2.55 \mathrm{~m} \mathrm{~s}^{-1}$ can be achieved at the measuring section, which fulfils the previously established requirements.

\subsubsection{Results of the Flow Characteristics Inside the WT}

For the calculation of the Reynolds numbers, the data from the sensor position $b$ from the measuring section was used, in which the hydraulic diameter for all calculations was $0.59 \mathrm{~m}$.

For a temperature of $12.11^{\circ} \mathrm{C}$ and an atmospheric pressure of $101.12 \mathrm{kPa}$, the kinematic viscosity was $1.44 \times 10^{-5} \mathrm{~m}^{2} \mathrm{~s}^{-1}$ (low fan speed). For a temperature of $10.32{ }^{\circ} \mathrm{C}$ and an atmospheric pressure of $101.14 \mathrm{kPa}$, the kinematic viscosity was $1.43 \times 10^{-5} \mathrm{~m}^{2} \mathrm{~s}^{-1}$ (medium fan speed). At a temperature of $9.96^{\circ} \mathrm{C}$, and an atmospheric pressure of $101.17 \mathrm{kPa}$, the kinematic viscosity was $1.42 \times 10^{-5} \mathrm{~m}^{2} \mathrm{~s}^{-1}$ (high fan speed). Thus, the calculation of the 
Reynolds numbers resulted in the rounded values of 10,000, 40,000 and 90,000 for the three set wind speeds. The high values indicate a turbulent flow within the test section.

To check the flow characteristics further, the turbulence intensity was calculated in addition to the Reynolds numbers. This resulted in $10.71 \%, 9 \%$ and $10.86 \%$ for the respective fan speed levels of low, medium and high. These figures also indicate a strong turbulent flow characteristic in the area of sensor position $b$.

\subsubsection{Results of the OPC Measurements with a Smooth Vertical Surface Installed}

The descriptive statistics of the assessed PM mass concentration and number concentration levels during the WT experiments by the OPC are displayed in Table 5. Overall, a slight variation can be seen for the input mass concentrations, with $\mathrm{PM}_{10}$ and $\mathrm{PM}_{2.5}$ in the pre-conditioning zone ranging between $38-44 \mu \mathrm{g} \mathrm{m}^{-3}$ and $13-19 \mu \mathrm{g} \mathrm{m}^{-3}$, respectively. The corresponding $\mathrm{PM}_{2.5} / \mathrm{PM}_{10}$ ratios were rather low for a near-roadside, semi-urban environment [30,31], stretching from 0.3 to 0.5 . Regarding number concentrations (lower size-cut of $0.25 \mu \mathrm{m}$ measured with the OPC), higher temporal variations were observed, ranging between $102 \mathrm{~cm}^{-3}$ and $200 \mathrm{~cm}^{-3}$. In general, these variations can be assigned to changes in meteorological conditions and source strength, e.g., traffic frequency (rush hour period). Figure 6 shows the mean number concentration size distribution determined in the pre-and post-conditioning zones measured by the OPCs amid varying fan speed levels. Here, the dominating influence of the particles in the lower size classes to the total particle number concentrations can be noticed. It can also be seen that the resulting number concentration distributions in the pre- and post-conditioning zone were indistinguishable with regard to the comparably low standard deviations for all midpoint optical particle diameters, visualized on a logarithmical scale in Figure 6. Additionally, an overall average particle number concentration of $2.6 \times 10^{-4} \mathrm{~cm}^{-3}$ (lower size cut at $6 \mathrm{~nm}$ aerodynamic diameters) was determined in the pre-conditioning zone using the electrical low-pressure impactor, yielding a value representative for a rural/urban background site [32].

Table 5. Assessed mean, median mass and number concentration levels in the pre- and postcondition zones during the experiments with varying fan speed levels and the associated removal rates connected with the results of the statistical tests.

\begin{tabular}{|c|c|c|c|c|c|c|c|c|c|c|c|c|c|}
\hline & & \multicolumn{3}{|c|}{$\mathbf{P M}_{10}$} & \multicolumn{3}{|c|}{$\mathrm{PM}_{2.5}$} & \multicolumn{3}{|c|}{$\mathbf{P M}_{1}$} & \multicolumn{3}{|c|}{$\mathrm{TC}(\mathrm{Dp}>0.25 \mu \mathrm{m})$} \\
\hline & & Mean & $\begin{array}{l}\text { Std. } \\
\text { Err. }\end{array}$ & Median & Mean & $\begin{array}{l}\text { Std. } \\
\text { Err. }\end{array}$ & Median & Mean & $\begin{array}{l}\text { Std. } \\
\text { Err. }\end{array}$ & Median & Mean & $\begin{array}{l}\text { Std. } \\
\text { Err. }\end{array}$ & Median \\
\hline $\begin{array}{c}\text { Fan speed } \\
\text { level }\end{array}$ & & \multicolumn{3}{|c|}{$\left(\mu \mathrm{g} \mathrm{m}^{-3}\right)$} & \multicolumn{3}{|c|}{$\left(\mu \mathrm{g} \mathrm{m}^{-3}\right)$} & \multicolumn{3}{|c|}{$\left(\mu \mathrm{g} \mathrm{m}^{-3}\right)$} & \multicolumn{3}{|c|}{$\left(\mathrm{cm}^{-3}\right)$} \\
\hline \multirow{4}{*}{$\begin{array}{c}\text { Low } \\
(n=60)\end{array}$} & Input (d) & 40.5 & \pm 1.6 & 40.3 & 13.1 & \pm 0.3 & 12.8 & 8.3 & \pm 0.2 & 7.9 & 102 & \pm 2.2 & 97 \\
\hline & Output (e) & 41.3 & \pm 1.7 & 40.9 & 13.0 & \pm 0.3 & 12.6 & 8.1 & \pm 0.2 & 7.8 & 97 & \pm 2.2 & 91 \\
\hline & $\begin{array}{l}\text { Removal } \\
\text { Rate }\end{array}$ & $0.8 \%$ & $\pm 2.7 \%$ & $0.6 \%$ & $1.2 \%$ & $\pm 2.1 \%$ & $1.8 \%$ & $2.9 \%$ & $\pm 2.1 \%$ & $2.9 \%$ & $5.7 \%$ & $\pm 2.2 \%$ & $6.4 \%$ \\
\hline & $\begin{array}{c}\text { Stat. } \\
\text { testresult }\end{array}$ & \multicolumn{3}{|c|}{ No sign. diff } & \multicolumn{3}{|c|}{ No sign. diff. } & \multicolumn{3}{|c|}{ Sign. diff. } & \multicolumn{3}{|c|}{ Sign. diff. } \\
\hline \multirow{4}{*}{$\begin{array}{l}\text { Medium } \\
(\mathrm{n}=35)\end{array}$} & Input (d) & 44.4 & \pm 1.8 & 41.2 & 17.3 & \pm 0.6 & 17.1 & 12.0 & \pm 0.5 & 11.9 & 156 & \pm 7.1 & 158 \\
\hline & Output (e) & 43.3 & \pm 1.8 & 43.3 & 16.8 & \pm 0.6 & 16.6 & 11.6 & \pm 0.5 & 11.3 & 144 & \pm 6.7 & 140 \\
\hline & $\begin{array}{c}\text { Removal } \\
\text { Rate }\end{array}$ & $5.2 \%$ & $\pm 3.0 \%$ & $0.4 \%$ & $4.6 \%$ & $\pm 2.9 \%$ & $2.0 \%$ & $5.0 \%$ & $\pm 2.4 \%$ & $2.7 \%$ & $9.3 \%$ & $\pm 2.0 \%$ & $7.7 \%$ \\
\hline & $\begin{array}{c}\text { Stat. } \\
\text { testresult }\end{array}$ & \multicolumn{3}{|c|}{ No sign. diff. } & \multicolumn{3}{|c|}{ No sign. diff. } & \multicolumn{3}{|c|}{ Sign. diff. } & \multicolumn{3}{|c|}{ Sign. diff. } \\
\hline \multirow{4}{*}{$\begin{array}{l}\text { High } \\
(n=25)\end{array}$} & Input (d) & 37.9 & \pm 2.6 & 37.4 & 18.9 & \pm 1.0 & 16.9 & 14.9 & \pm 1.0 & 12.4 & 200 & \pm 13.8 & 164 \\
\hline & Output (e) & 36.6 & \pm 2.3 & 35.6 & 18.7 & \pm 1.0 & 18.2 & 14.8 & \pm 1.0 & 13.1 & 191 & \pm 13.1 & 170 \\
\hline & $\begin{array}{l}\text { Removal } \\
\text { Rate }\end{array}$ & $5.4 \%$ & $\pm 3.9 \%$ & $5.1 \%$ & $2.9 \%$ & $\pm 2.1 \%$ & $0.9 \%$ & $1.9 \%$ & $\pm 1.9 \%$ & $-0.6 \%$ & $5.7 \%$ & $\pm 1.5 \%$ & $5.0 \%$ \\
\hline & $\begin{array}{c}\text { Stat. } \\
\text { testresult }\end{array}$ & \multicolumn{3}{|c|}{ No sign. diff. } & \multicolumn{3}{|c|}{ No sign. diff. } & \multicolumn{3}{|c|}{ No sign. diff. } & \multicolumn{3}{|c|}{ Sign. diff. } \\
\hline
\end{tabular}




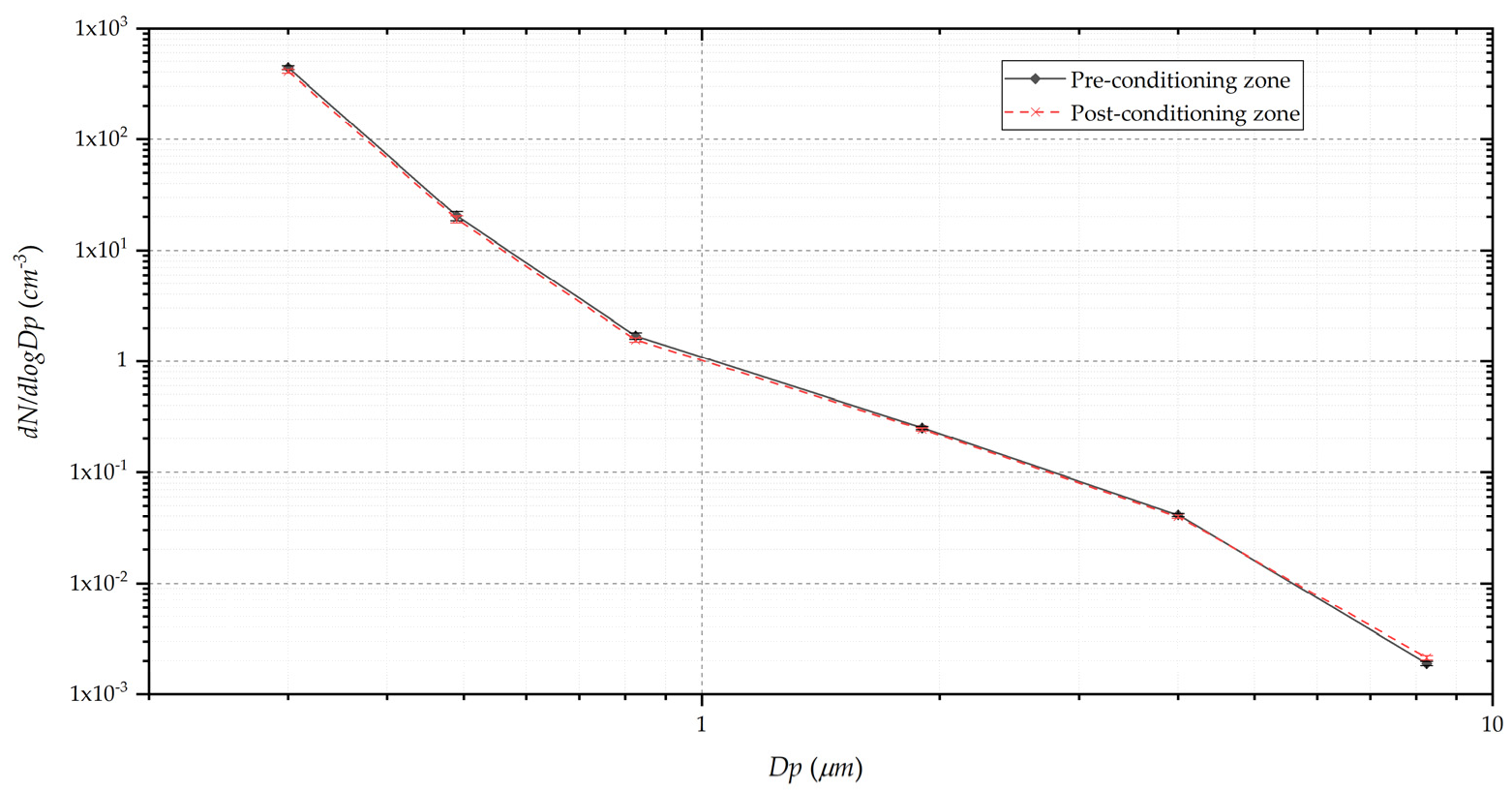

Figure 6. Measured number concentration size distribution normalized against midpoint optical particle diameter $(\mathrm{dN} / \mathrm{d} \log \mathrm{Dp})$ during the whole period of the WT experiments in the pre- and post-conditioning zones by the two OPCs.

To assess possible PM losses inside the WT, the data sets measured by the two OPCs installed in the pre- and post-conditioning zones were used to calculate the removal rates according to the procedure given by Ji et al., where the measured atmospheric concentration values for the assessed parameters in the pre-conditioning $\left(C_{i n}\right)$ and post-conditioning zones $\left(C_{\text {out }}\right)$ were adopted suitably [33].

$$
\text { Removal Rate in } \%=\left(C_{\text {in }}-C_{\text {out }}\right) / C_{\text {out }} * 100
$$

The calculations were based on the paired minute averages. Further on, statistical tests, used earlier for the comparability assessment of both instruments, were employed to indicate significantly different PM concentrations in front and behind the measuring section.

Comparing total number concentrations (TC, lower size cut $0.25 \mu \mathrm{m}$ ), concentrations in the pre-conditioning zone were statistically higher for all experiments. The mean removal rates of TC yielded $6 \%, 9 \%$ and $6 \%$ for the low, medium, and high flow speed levels, respectively. Moreover, $\mathrm{PM}_{1}$ mass concentrations at the post-conditioning zone were slightly but consistently lower than the concentration levels at the pre-condition zone. The statistical tests indicated significant differences for low and midpoint flow speeds. The obtained mean removal rates were 3\% for the low fan speed level and 5\% for the midpoint fan speed. For the trial run with the highest flow speed levels (removal rate $2 \%$ ) no statistically significant difference between the inflow and outflow concentrations was obtained. The calculated mean $\mathrm{PM}_{2.5}$ removal rates varied for the different fan speed levels, reaching $1 \%, 5 \%$ and $3 \%$ for the low, medium, and high flow speeds, respectively, but the statistical tests showed no significant differences for either experiment. A similar result was obtained for the mass concentration of $\mathrm{PM}_{10}$. The measurements showed marked variations between the pre- and post-condition zones and consequently the obtained removal rates ( $1 \%$ amid low and circa $5 \%$ for both medium and high fan speed levels) were not significant.

In addition to the overall mean removal rates, Table 5 displays the median removal rate, which is more robust against outliers. Regarding the results that were previously stated as statistically significant concentration changes, the median and mean removal rates were consistent and a net PM removal inside the WT was visible. Removal rates which were regarded as statistically non-significant, on the other hand, showed divergences between the median and mean values, yielding even negative median removal rates concerning 
the PM size fraction at a high fan speed level. This underlines the importance of testing removal rates for their statistical significance before removal or before the resuspension tendencies are evaluated.

The higher variability of the data for mass concentrations is further illustrated in Figure 7, which displays the relationship of the measured minute average values of TC and $\mathrm{PM}_{2.5}$ at the midpoint fan speed level (flow speed $\sim 1 \mathrm{~m} \mathrm{~s}^{-1}$ ) and the respective errors which have to be considered for the single measurements and were calculated as given in the Methods section (Section 2.3.1). The larger errors of $\mathrm{PM}_{2.5}$ data points are also reflected by the more pronounced scatter of calculated mass concentrations. The uncertainty of the evaluation of a net deposition or resuspension process inside the tunnel becomes apparent. The effect is even stronger for the TSP and $\mathrm{PM}_{10}$ relationships. Both the scatterand comparably high error-ranges concerning the $\mathrm{PM}_{10}$ and $\mathrm{PM}_{2.5}$ parameters, measured by the portable OPC instruments have to be taken into account before deposition or before the resuspension processes are interpreted.
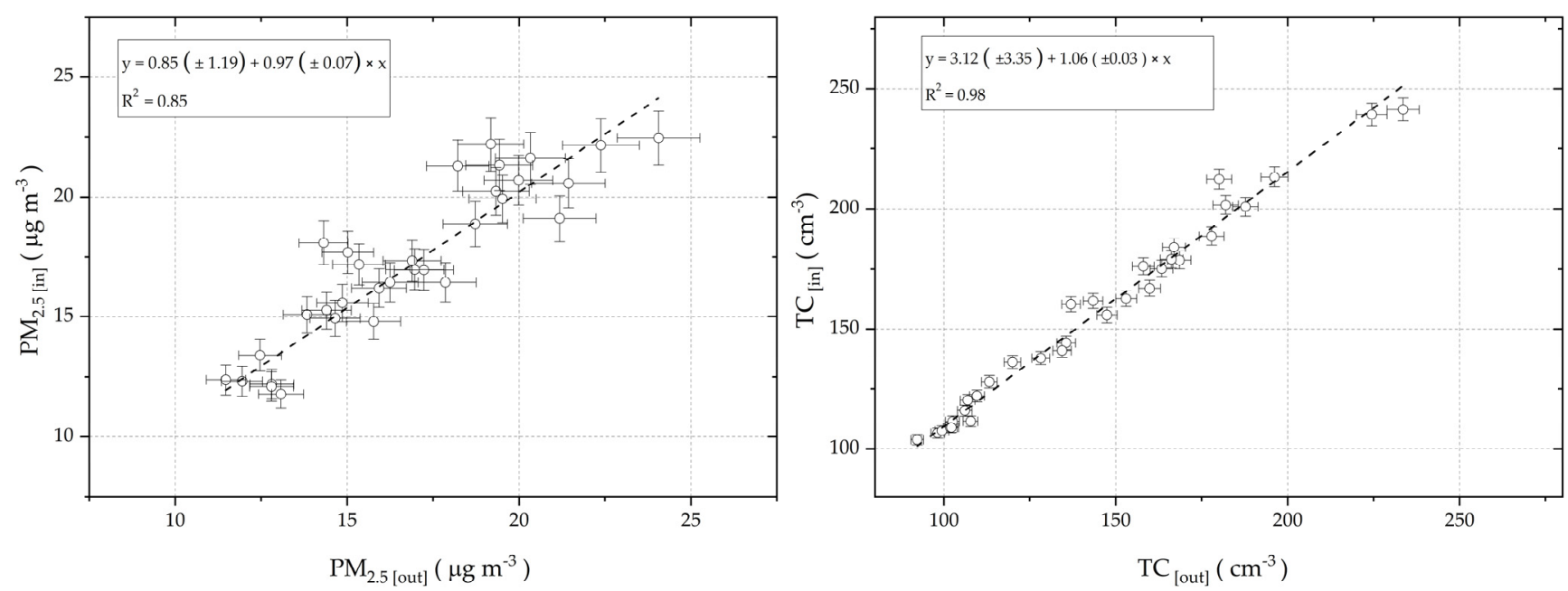

Figure 7. Relationship between the measured input and output minute concentration averages for $\mathrm{PM}_{2.5}$ and TC in the WT experiment during the midpoint fan speed level. Error bars correspond to average relative discrepancies presented in Section 2.3.1.

\section{Discussion}

The aim of the study was to develop a modular, transportable WT to determine the collection efficiency of PM on surfaces with ambient air, taking atmospheric parameters into account.

The results of the literature research served to develop a requirements profile and provided a basic overview of the different $\mathrm{WT}$ designs, technical installations and measuring equipment used. The resulting data on the construction materials was rather difficult to determine, as most of the data were not available. Due to the simple handling and for financial reasons, the construction for our WT was made of wood.

A conscious decision was made in favor of an open construction method for our WT, following the division of the zones described in Cattafest et al. [13], Valera et al. [26] and Franco et al. [25], which are referred to here as the pre- and post-conditioning zones, the measuring section and the test section, respectively. The main advantage of open constructions is the small space requirement. The external influences such as temperature, relative humidity and wind influences, which can lead to an increase in turbulence in the interior, were taken into account. In addition, a closed construction can achieve higher wind speeds with the same energy [13]. In order to minimize external influences, our WT could be used in a climate chamber due to its modular design and size, in a similar way to the TEWT WT for complete climate control [21]. The technical installations used in our WT were limited to ultrasonic anemometers and temperature and humidity sensors. To 
minimize costs, we did not use digital high-speed cameras and three-dimensional real-time scanners as used in other constructions [29]. As a suggestion for optimization and to track the external influences such as gust wind speeds, additional sensors should be installed outside our WT.

A special feature of our WT is its modular construction and compact size. The fact that the WT, with an overall length of $4.33 \mathrm{~m}$, fits on a conventional open car trailer means that measurements in inner-city areas with varying local PM concentrations are possible and easy to arrange. This will enable microclimatic data to be generated close to buildings or streets. In addition to the height of $0.5 \mathrm{~m}$ to $1.74 \mathrm{~m}$ above the ground, our WT also offers the possibility to measure at a realistic height for humans and larger animals, referring to the breathing zone. This will allow conclusions to be drawn about human health in further studies in an urban environment, and thus also the potential for PM deposition from facade surfaces such as plaster, masonry, glass, but similarly facade greening and plants to be studied.

By defining the planned test section with the specified requirement of a $1 \mathrm{~m}^{2}$ vertical surface area for easier extrapolation of, for example, building facades, also imposed limitations due to the resulting relatively large cross-section of $0.44 \mathrm{~m}^{2}$ at the maximum flow speed of $2.55 \mathrm{~m} \mathrm{~s}^{-1}$ to be achieved in this area. Lower wind speeds showed an increased standard deviation of $11.03^{\circ}$ at sensor position a. These values indicated different angles of attack relative to the main wind flow. Depending on the area of application, this could lead to problems and complicate the comparability with WTs operated with laminar flows. Nevertheless, as shown in a study by Price et al., when investigating vegetation, the angle of the leaf relative to the wind direction had no measurable influence on a possible deposition fraction [34].

Likewise, the theoretical Reynolds numbers and the measured turbulence intensity values showed that a rather turbulent flow prevailed at the test section. The obtained turbulence intensities were comparable to the measured wind velocity variation levels in urban areas [35]. To reduce this turbulence, a honeycomb structure has been used in other studies in the pre-conditioning zone [21,22]. Thereby, the incoming flows meet the test section with less turbulence, which could easily be realized for our WT. To convert the laminar flow into isotropic turbulence, the study by Price et al. used grating bars in front of the test surface to create turbulences. These have been found to increase the deposition potential of vegetative structures [34]. Further on, the employment of scaled down urban roughness elements in the pre-condition zone can potentially enhance turbulence intensities [36]. The adoption of additional downsized model buildings at the test section could further expand the experimental possibilities inside our WT [37], simulating the different flow behaviors of modeled street canyons with varying aspect ratios [38].

Overall, statistically significant removal rates, implicating a net deposition process inside our WT with smooth vertical surfaces, ranged between $3 \%$ and $9 \%$ and were only relevant for $\mathrm{PM}_{1}$ and $\mathrm{TC}$ parameters. The highest removal rates were measured during the setup with the midpoint fan speed level (mean overall flow speed of $1.2 \mathrm{~m} \mathrm{~s}^{-1}$ ), reaching $4 \%$ and $9 \%$ for the $\mathrm{PM}_{1}$ and TC variables, respectively. Likewise, significant $\mathrm{PM}_{1}$ and TC removal rates were found for the measurement with a low flow speed (mean overall flow speed of $0.5 \mathrm{~m} \mathrm{~s}^{-1}$ ), with $3 \%$ and $6 \%$, accordingly. For a high fan speed level (mean overall flow speed of $2.5 \mathrm{~m} \mathrm{~s}^{-1}$ ) only the mean removal rate of the total counts was significant, amounting to $5 \%$. Considering the overall measurement error regarding the $\mathrm{PM}_{10}$ and $\mathrm{PM}_{2.5}$ parameters and examining the subsequent statistical analyses, no significant removal rates could be found for the respective mass concentrations.

These values are sufficiently low, considering the actual removal rates by trees and buildings achieved in a similar setup by Ji et al. [33], despite the use of different WT dimensions, emission sources and measuring instruments. Ji et al. investigated the influence of trees, modeled by tree branches, around scaled miniature buildings on $\mathrm{PM}_{2.5}$ spatial distribution and removal efficiency, comparing the results achieved in experiments with 
and without the modeled vegetation in a wind tunnel environment. Here, they found an enhanced $\mathrm{PM}_{2.5}$ removal rate of $20 \%$ by the employed tree species in comparison to the tree-free scenario. At the same time, the assessed $\mathrm{PM}_{2.5}$ removal rate in the tunnel with only the model buildings in the absence of the model trees was $56 \%$ [33].

\section{Conclusions}

We hereby presented a wind tunnel to investigate the interaction of PM on surface structures. As previous studies have shown, the shapes and dimensions of different wind tunnels vary greatly. Therefore, as in this study, adaptations are made to the area of application. Each of these WTs has its limitations in certain areas. In our case, it was the influence of temperature and humidity, as well as the maximum flow speed. Due to the open construction and the accompanying external influence on the flow behavior in the WT, the flow speed data should be recorded in the same way and additionally in the outside area of the WT in future experiments to make correlations visible. The evaluated blank PM removal rates showed only minor losses, although the values of up to $10 \%$ for total particle counts $(\mathrm{Dp}>0.25 \mu \mathrm{m})$ were still statistically significant and showed a maximum of significant value of $5 \%$ for $\mathrm{PM}_{1}$ mass concentrations. The $\mathrm{PM}_{10}$ and $\mathrm{PM}_{2.5}$ removal rates inside the blank tunnel were statistically not significant. Despite its limitations, this WT could be a useful tool with only minor optimizations for future studies on different surfaces such as rendered facades, green facades, glass facades, etc. to determine their PM collection efficiency. Furthermore, due to the adaptability of the test section, our WT could be modified to examine different street canyon aspect ratios [37-39]. Thus, the removal efficiencies of PM amid model buildings and model trees [33] over varying flow conditions could be tested. Based on these observations, further recommendations could be made in urban areas that can contribute to human and ecosystem health. Due to the negative public health aspects associated with PM, the WT allowed measurements to be taken at a height of $0.5-1.74 \mathrm{~m}$, in the range of the size of humans and animals. As a result of the architecture (mobility, modularity) of the presented wind tunnel, PM exposition measurements in different urban contexts could be performed, which brings a unique characteristic to this WT. Based on that knowledge, urban greening interventions could be planned in areas with high exposition risks, consequently reducing the negative public health effects of PM. Overall, our WT is a useful tool to identify surfaces as air cleaners and thus makes a crucial contribution to the research on air cleaning in urban areas, which is of great importance for public health.

Author Contributions: Conceptualization, P.S., U.P., B.S., J.I. and T.P.; methodology, P.S., A.G., U.P., J.I., A.K.-G. and T.P.; validation, U.P., J.I., A.K.-G. and D.H.; formal analysis, A.G. and P.S.; investigation, P.S. and A.G.; data curation, P.S. and A.G.; writing—original draft preparation, P.S. and A.G.; writing-review and editing, P.S., A.G., S.T., J.I., T.P., A.K.-G., D.H., L.C., B.S. and U.P.; visualization, P.S. and A.G.; supervision, U.P., A.K.-G.; project administration, J.I.; funding acquisition, J.I. All authors have read and agreed to the published version of the manuscript.

Funding: This research was funded by the Austrian Science Fund FWF, grant number P 33099-N. "Open Access Funding by the Austrian Science Fund (FWF)".

Institutional Review Board Statement: Not applicable.

Informed Consent Statement: Not applicable.

Acknowledgments: Many thanks to Johann Rutzenholzer, who contributed significantly to the construction of the wind tunnel and to the study site team in Groß-Enzersdorf for their active support during the field experiment. We also thank the City of Vienna, Municipal Department Environmental Protection (MA-22) for providing one of the OPCs. Further we want to thank Epina $\mathrm{GmbH}$ for supplying us with a free research license of DataLab (http:/ / datalab.epina.at) (accessed on 9 December 2020).

Conflicts of Interest: The authors declare no conflict of interest. 


\section{References}

1. European Environment Agency. Air Quality in Europe-2020 Report; EEA Report; No 9/2020; European Environment Agency: Copenhagen, Denmark, 2020; ISBN 9789294802927.

2. Kampa, M.; Castanas, E. Human health effects of air pollution. Environ. Pollut. 2008, 151, 362-367. [CrossRef]

3. World Health Organization. Health Effects of Particulate Matter; WHO Regional Office for Europe: Copenhagen, Denmark, 2013; Volume 91, pp. 106-113. [CrossRef]

4. Kiesewetter, G.; Schoepp, W.; Heyes, C.; Amann, M. Modelling PM2.5 impact indicators in Europe: Health effects and legal compliance. Environ. Model. Softw. 2015, 74, 201-211. [CrossRef]

5. Przybysz, A.; Nersisyan, G.; Gawroński, S.W. Removal of particulate matter and trace elements from ambient air by urban greenery in the winter season. Environ. Sci. Pollut. Res. 2019, 26, 473-482. [CrossRef] [PubMed]

6. Wania, A.; Bruse, M.; Blond, N.; Weber, C. Analysing the influence of different street vegetation on traffic-induced particle dispersion using microscale simulations. J. Environ. Manag. 2012, 94, 91-101. [CrossRef] [PubMed]

7. Xing, Y.; Brimblecombe, P. Role of vegetation in deposition and dispersion of air pollution in urban parks. Atmos. Environ. 2019, 201, 73-83. [CrossRef]

8. Abhijith, K.V.; Kumar, P.; Gallagher, J.; McNabola, A.; Baldauf, R.; Pilla, F.; Broderick, B.; Di Sabatino, S.; Pulvirenti, B. Air pollution abatement performances of green infrastructure in open road and built-up street canyon environments-A review. Atmos. Environ. 2017, 162, 71-86. [CrossRef]

9. Marando, F.; Salvatori, E.; Fusaro, L.; Manes, F. Removal of PM10 by forests as a nature-based solution for air quality improvement in the Metropolitan city of rome. Forests 2016, 7, 150. [CrossRef]

10. Irga, P.J.; Paull, N.J.; Abdo, P.; Torpy, F.R. An assessment of the atmospheric particle removal efficiency of an in-room botanical biofilter system. Build. Environ. 2017, 115, 281-290. [CrossRef]

11. Gopalakrishnan, V.; Ziv, G.; Hirabayashi, S.; Bakshi, B.R. Nature-Based Solutions Can Compete with Technology for Mitigating Air Emissions across the United States. Environ. Sci. Technol. 2019, 53, 13228-13237. [CrossRef]

12. Cattafesta, L.; Bahr, C.; Mathew, J. Fundamentals of Wind-Tunnel Design. Encycl. Aerosp. Eng. 2010, 1-10. [CrossRef]

13. Zhang, J.; Li, J.; Li, A.; Wang, Y.; Chen, W. Study on Motion and Deposition of Particles in a Wind Tunnel. Procedia Eng. 2015, 121, 450-458. [CrossRef]

14. Sippola, M.R.; Nazaroff, W.W. Particle Deposition from Turbulent Flow: Review of Published Research and Its Applicability to Ventilation Ducts in Commercial Buildings. Lawrence Berkeley National Laboratory, LBNL 51432. 2020. Available online: https:/ / escholarship.org/uc/item/9cg365f5 (accessed on 23 March 2021).

15. Dai, W.; Davidson, C.I.; Etyemezian, V.; Zufall, M. Wind tunnel studies of particle transport and deposition in turbulent boundary flows. Aerosol Sci. Technol. 2001, 35, 887-898. [CrossRef]

16. Lu, H.; Wang, Y. Particle deposition in ventilation ducts: A review. Build. Simul. 2019, 12, 723-734. [CrossRef]

17. Roupsard, P.; Amielh, M.; Maro, D.; Coppalle, A.; Branger, H.; Connan, O.; Laguionie, P.; Hebert, D.; Talbaut, M. Measurement in a wind tunnel of dry deposition velocities of submicron aerosol with associated turbulence onto rough and smooth urban surfaces. J. Aerosol Sci. 2013, 55, 12-24. [CrossRef]

18. Jiang, H.; Lu, L.; Sun, K. Simulation of particle deposition in ventilation duct with a particle-wall impact model. Build. Environ. 2010, 45, 1184-1191. [CrossRef]

19. White, M. Frank Fluid Mechanics, 7th ed.; McGraw-Hill: New York, NY, USA, 1979; ISBN 978-0-07-352934-9.

20. Mckenna Neuman, C.; Maljaars, M. Wind tunnel measurement of boundary-layer response to sediment transport. Boundary-Layer Meteorol. 1997, 84, 67-83. [CrossRef]

21. Richards-Thomas, T.; McKenna-Neuman, C. Wind Tunnel-Based Comparison of PM10 Emission Rates for Volcanic Ash and Glaciogenic Aerosol Sources Within Iceland. J. Geophys. Res. Atmos. 2020, 125, 1-18. [CrossRef]

22. Preston, C.A.; McKenna Neuman, C.; Boulton, J.W. A wind tunnel and field evaluation of various dust suppressants. J. Air Waste Manag. Assoc. 2020, 70, 915-931. [CrossRef]

23. Katra, I. Comparison of diverse dust control products in wind-induced dust emission from unpaved roads. Appl. Sci. 2019, 9, 5204. [CrossRef]

24. Katra, I.; Elperin, T.; Fominykh, A.; Krasovitov, B.; Yizhaq, H. Modeling of particulate matter transport in atmospheric boundary layer following dust emission from source areas. Aeolian Res. 2016, 20, 147-156. [CrossRef]

25. Franco, A.; Fernández-Cañero, R.; Pérez-Urrestarazu, L.; Valera, D.L. Wind tunnel analysis of artificial substrates used in active living walls for indoor environment conditioning in Mediterranean buildings. Build. Environ. 2012, 51, 370-378. [CrossRef]

26. Valera, D.L.; Álvarez, A.J.; Molina, F. Aerodynamic analysis of several insect-proof screens used in greenhouses. Span. J. Agric. Res. 2006, 4, 273-279. [CrossRef]

27. Mahmoodabadi, M.; Zamani, S.; Yazdanpanah, N. Enrichment of soil organic carbon in the eroded sediments due to the simultaneous occurrence of rain and wind. Geoderma 2021, 386, 114926. [CrossRef]

28. Kheirabadi, H.; Mahmoodabadi, M.; Jalali, V.; Naghavi, H. Sediment flux, wind erosion and net erosion influenced by soil bed length, wind velocity and aggregate size distribution. Geoderma 2018, 323, 22-30. [CrossRef]

29. Trent Wind Tunnel Laboratory TEWT. Available online: https://sites.google.com/view/tewt-at-trent/home (accessed on 23 March 2021). 
30. Rovelli, S.; Cattaneo, A.; Borghi, F.; Spinazzè, A.; Campagnolo, D.; Limbeck, A.; Cavallo, D.M. Mass concentration and sizedistribution of atmospheric particulate matter in an urban environment. Aerosol Air Qual. Res. 2017, 17, 1142-1155. [CrossRef]

31. Spangl, W.; Nagl, C. Jahresbericht der Luftgütemessungen in Österreich 2014; Umweltbundesamt GmbH: Vienna, Austria, 2015; ISBN 9783990041864 .

32. Cassee, F.R.; Morawska, L.; Peters, A. Ambient Ultrafine Particles: Evidence for Policy Makers; "White Paper"; Bilthoven, The Netherlands, 2019. Available online: https://www.researchgate.net/publication/337111816_Ambient_ultrafine_particles_ evidence_for_policy_makers_A_report_prepared_by_the_\%27Thinking_outside_the_box\%27_team (accessed on 23 March 2021).

33. Ji, W.; Zhao, B. A wind tunnel study on the effect of trees on PM2.5 distribution around buildings. J. Hazard. Mater. 2018, 346, 36-41. [CrossRef] [PubMed]

34. Price, T.A.; Stoll, R.; Veranth, J.M.; Pardyjak, E.R. A wind-tunnel study of the effect of turbulence on PM10 deposition onto vegetation. Atmos. Environ. 2017, 159, 117-125. [CrossRef]

35. Emeis, S.; Baumann-stanzer, K.; Piringer, M.; Kallistratova, M.; Kouznetsov, R.; Yushkov, V. Wind and turbulence in the urban boundary layer-Analysis from acoustic remote sensing data and fit to analytical relations. Meteorol. Z. 2007, 16, 393-406. [CrossRef]

36. Mo, Z.; Liu, C.H. Wind tunnel measurements of turbulent boundary layer flows over arrays of ribs and cubes. Geosci. Lett. 2018, 5,1-10. [CrossRef]

37. Vardoulakis, S.; Fisher, B.E.; Pericleous, K.; Gonzalez-Flesca, N. Modelling air quality in street canyons: A review. Atmos. Environ. 2014, 37, 155-182. [CrossRef]

38. Chew, L.W.; Aliabadi, A.A.; Norford, L.K. Flows across high aspect ratio street canyons: Reynolds number independence revisited. Environ. Fluid Mech. 2018, 18, 1275-1291. [CrossRef]

39. Baik, J.J.; Park, R.S.; Chun, H.Y.; Kim, J.J. A laboratory model of urban street-canyon flows. J. Appl. Meteorol. 2000, 39, 1592-1600. [CrossRef] 